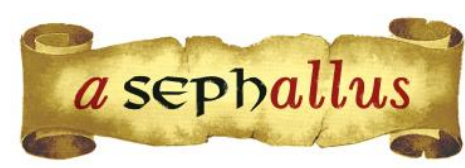

Revista aSEPHallus de Orientação Lacaniana

Núcleo Sephora de Pesquisa sobre o Moderno e o Contemporâneo

ISSN $1809-709 \mathrm{X}$

\title{
Help line: relato de experiência sobre um dispositivo de acolhimento aos profissionais de saúde durante a pandemia covid-19
}

Tania Coelho dos Santos

Orcid: https://orcid.org/0000-0002-5360-7864

Pós-doutorado no Departamento de Psicanálise de Paris VIII (Paris, França)

Professor Associado, nível IV no Programa de Pós-graduação em Teoria Psicanalítica/UFRJ (Rio de Janeiro, Brasil)

Pesquisadora Bolsista de Produtividade Científica do CNPQ nível $1 \mathrm{C}$

Presidente do Instituto Sephora de Ensino e Pesquisa de Orientação Lacaniana/ ISEPOL (Rio de Janeiro, Brasil)

Psicanalista Membro da École de La Cause Freudienne, da Escola Brasileira de Psicanálise e da Associação

Mundial de Psicanálise

Membro da Associação Universitária de Pesquisa em Psicopatologia Fundamental (Rio de Janeiro, Brasil)

E-mail: taniacs@openlink.com.br

Fernanda Saboya Almendra

ORCID ID: 0000-0001-8429-9705

Graduada em Psicologia pela Universidade Federal do Rio de Janeiro

Especialista em Psicologia Médica pela FCM-UERJ (Rio de Janeiro, Brasil)

Membro do Instituto Sephora de Ensino e Pesquisa de Orientação Lacaniana (ISEPOL)

Integrante do projeto de extensão "Psicanálise aplicada à prática do psicólogo no hospital" pelo PPGTP- UFRJ.

Presidente do Departamento de Psicologia da Associação de Medicina Intensiva Brasileira (AMIB - gestão 2020-

2021)

Coordenadora do Serviço de Psicologia dos Hospitais Copa D’Or, Copa Star e Glória D'Or Email: fernanda_saboya@yahoo.com.br

Manuella Itapary Ribeiro

ORCID ID: 0000-0002-368-8905

Graduada em Psicologia pela Pontifícia Universidade Católica (Rio de Janeiro, Brasil) Mestre em Teoria Psicanalítica pela Universidade Federal do Rio de Janeiro/UFRJ (Rio de Janeiro/Brasil) Membro Associado do Instituto Sephora de Ensino e Pesquisa de Orientação Lacaniana (ISEPOL) Psicóloga dos Hospitais Copa D’Or e Copa Star e Glória D’Or Integrante do projeto de extensão "Psicanálise aplicada à prática do psicólogo no hospital: prevenção de transtornos psicológicos dos colaboradores nas instituições hospitalares da Rede D’Or

E-mail: manuitapary@hotmail.com

Resumo: A pandemia de Covid-19 conduziu a um aumento súbito e de crescimento imprevisível da demanda por serviços médico-hospitalares $\mathrm{O}$ reconhecimento da sobrecarga emocional e de trabalho da equipe multidisciplinar exigiu do serviço de psicologia novas estratégias de atenção à saúde mental dos funcionários. Por meio de uma linha telefônica, foi possível prestar atendimento psicológico aos colaboradores em urgência subjetiva, pois a crise na saúde da população em geral repercutiu diretamente na saúde física e mental dos profissionais que trabalham nos hospitais.

Palavras-chave: pandemia; psicanálise aplicada no hospital; assistência psicológica ao colaborador; angústia; urgência subjetiva.

Help line: rapport d'expérience sur un dispositif d'accueil pour les professionnels de la santé pendant la pandémie de covid-19.: La pandémie de Covid-19 a entraîné une augmentation soudaine et 
imprévisible de la demande de services médico-hospitaliers. La reconnaissance de la surcharge émotionnelle et de travail de l'équipe multidisciplinaire a obligé le département de psychologie à développer de nouvelles stratégies pour les soins de santé mentale du personnel. Pour répondre à ce besoin, une nouvelle approche a été instituée, dans laquelle il était possible de fournir des soins psychologiques aux employés en cas d'urgence subjective par le biais d'une ligne téléphonique, étant donné que la crise de la santé de la population en général avait eu un effet direct sur la santé physique et mentale des professionnels travaillant dans les hôpitaux.

Mots-clés : pandémie; psychanalyse appliquée à l'hôpital; assistance psychologique au collaborateur; angoisse; urgence subjective.

Help line: experience report on a welcoming device for health professionals during the covid-19 pandemic.: The Covid-19 pandemic led to a sudden and unpredictable increase in demand for medical-hospital services. The recognition of the emotional and work overload of the multidisciplinary team required the psychology department to develop new strategies for staff mental health care. To meet this need, a new approach was instituted, which enabled to provide psychological care to employees in a subjective emergency, since the crisis in the health of the population in general had a direct impact on the physical and mental health of professionals who work in hospitals.

Keywords: pandemic; psychoanalysis applied in the hospital; psychological assistance to the collaborator; anguish; subjective urgency. 


\section{Help line: relato de experiência sobre um dispositivo de acolhimento aos profissionais de saúde durante a pandemia covid-19}

Tania Coelho dos Santos, Fernanda Saboya Almendra \& Manuela Itapary Ribeiro

\section{A psicanálise aplicada}

A pandemia de Covid-19 conduziu a um aumento súbito e de crescimento imprevisível da demanda por serviços médico-hospitalares. Nesse contexto a crise na saúde da população em geral repercutiu diretamente na saúde física e mental dos profissionais que trabalham nos hospitais (OMS, 2020). A pressão sobre a saúde desses trabalhadores foi intensificada pelas alterações emergenciais na rotina laboral. Pudemos dar nosso testemunho acerca de alguns cenários em que essa situação se expressou nos seguintes artigos: Dias, Coelho dos Santos, Pereira, Rodrigues e Costa (2019), Saboya, Coelho dos Santos, Moreira e Castro (2019), e Moreira e Coelho dos Santos (2019). Essa nova publicação faz parte, portanto, de uma série de trabalhos acerca da psicanálise aplicada à prática do psicólogo no hospital e, em particular, à saúde do trabalhador.

Para nós psicólogos que, seguindo a orientação lacaniana (Coelho dos Santos, 2005) nos dedicamos a aplicar a psicanálise à assistência hospitalar para obter bons efeitos terapêuticos, encontramos um desafio inédito. A sobrecarga emocional da equipe multiprofissional gerada pela inexperiência no combate à epidemia e pela rotina de trabalho alterada, nos conduziu a desenvolver um novo dispositivo para intervenção rápida nas crises de angústia agudas e outras desordens psíquicas associadas a ela, apresentadas pelos colaboradores de hospitais da Rede D’Or. No programa de psicanálise aplicada à saúde dos colaboradores, junto à medicina do trabalho, há alguns anos desenvolvemos um dispositivo clínico voltado para o diagnóstico, tratamento e prevenção de transtornos psicológicos que repercutem na vida profissional. 0 acompanhamento psicanalítico de profissionais da instituição que desencadeiam intenso mal-estar psíquico no ambiente de trabalho, é uma iniciativa que resultou da ampliação de um projeto de extensão em psicanálise aplicada (Coelho dos Santos, 2020b) que já vinha sendo desenvolvido em outra instituição hospitalar. Segundo Coelho dos Santos (2020a):

A psicanálise é uma prática que legitima a irrupção do privado no espaço público. Trata-se de um dispositivo que repousa sobre uma variante do contrato entre médico e paciente. Esse espaço público não é o espaço do diálogo. A comunicação dá lugar a um dizer que não comporta necessariamente uma resposta simétrica e intersubjetiva. O dispositivo analítico rompe com as regras que regulam a comunicação entre pessoas adultas nas relações sociais normais. Nele, o silêncio do analista não é sinônimo de falta de educação. Este tipo muito

Revista aSEPHallus de Orientação Lacaniana. Rio de Janeiro, 15(30), 26-40, mai. 2020 a out. 2020.

Help line: relato de experiência sobre um dispositivo de acolhimento aos profissionais de saúde durante

a pandemia covid-19

Tania Coelho dos Santos, Fernanda Saboya Almendra \& Manuela Itapary Ribeiro 
peculiar de laço social pode ser transportado para outros espaços públicos que são regulamentados de forma diversa deste? (Coelho dos Santos, 2020a, p.147-158)

Neste artigo, a autora e supervisora do serviço, se pergunta também se o analista pode praticar essa dissimetria fora de um contrato privado entre as quatro paredes do consultório particular? Que alterações é preciso introduzir nesta prática para estendê-la à assistência a pacientes internados em hospitais ou aos profissionais que aí exercem suas funções, por exemplo, sem abandonar os princípios que justificam sua excepcionalidade?

Em outro artigo, algumas participantes dessa pesquisa (Oliveira, Coelho dos Santos, Dias \& Carvalho, 2019, p. 160) esclarecem que se apoiaram na experiência dos CPCT/Paris (Centre Psychanalytique de Consultations et de Traitement), entidade criada pela École de la Cause Freudienne para atendimento gratuito à população. Deste dispositivo, tomaram emprestado o número médio de entrevistas que foi fixado entre quatro e doze sessões. Depois dessas entrevistas preliminares é formulada uma hipótese diagnóstica sobre a estrutura psíquica do sujeito. É preciso, preliminarmente, distinguir as manifestações do inconsciente típicas da psicose (delírios e alucinações) daquelas típicas da neurose (sintomas) cujos enredos fantasmáticos explicam seus impasses diante dos limites impostos pela realidade aos seus anseios. Sempre que existe da parte do funcionário uma demanda de continuar esse tratamento, procuramos um psicólogo externo ligado a um plano de saúde para acompanhá-lo.

Os resultados preliminares levaram à conclusão de que embora o transtorno psicológico seja desencadeado no trabalho, não se origina, necessariamente, das exigências impostas pelo desempenho profissional. Não se trata, obrigatoriamente, de estresse ocupacional. Por esta razão é preciso avaliar, caso a caso, qual é o impasse velado sob uma mudança de comportamento, alteração do humor, problemas nos relacionamentos interpessoais com colegas de trabalhos, lideranças e chefias. A cada caso é preciso verificar se podemos levar o colaborador a efetuar uma retificação subjetiva na relação com sua função laboral, com sua chefia, com seus pares e com a própria instituição.

A pandemia de Covid-19 impôs a todos um desafio: lidar com um evento inesperado e com consequências imponderáveis. Este vírus imprevisível expôs o corpo humano a uma possível vulnerabilidade extrema e incontornável. No começo dela, um grande número de colaboradores inexperientes, exaustos e sem equipamentos de proteção individual suficientes e seguros, desencadeou um estado de angústia cuja manifestação podia variar de leve à incapacitante. Nos hospitais em que trabalhamos, esse encontro com o imprevisível provocou, eventualmente, uma desordem subjetiva como resposta à contingência ameaçadora que os remeteu à experiência do desamparo originário.

Revista aSEPHallus de Orientação Lacaniana. Rio de Janeiro, 15(30), 26-40, mai. 2020 a out. 2020.

Help line: relato de experiência sobre um dispositivo de acolhimento aos profissionais de saúde durante 


\section{O desamparo e o Outro}

Sabemos que a imaturidade biológica e psíquica do ser humano ao nascer coloca-o em situação de total dependência do Outro materno. A essência deste estado é a solidão. A experiência de impotência que o acompanha é o resultado da impossibilidade do sujeito de encontrar sozinho uma saída para a necessidade urgente em que se encontra. Assim, sua sobrevivência está desde o início da vida à mercê do desejo do Outro. Essa referência psicológica é decisiva e marcará de forma estruturante tanto a posição do sujeito no laço social quanto à formação de suas representações do mundo, suas expectativas, seus sonhos e suas ilusões. A resposta do Outro à manifestação das necessidades do ser humano em estado de desamparo é fundamental para a constituição do aparelho psíquico. Dela depende que ele estabeleça com o Outro uma relação de confiança, que the permita esperar que sua necessidade de amor e de proteção vai ser atendida.

Freud (1950[1895]/1996) chamou de desamparo (Hilflosigkeit) a este estado de impotência no qual se encontra a criança recém-nascida. Segundo o autor, é no desamparo primordial que pode ser localizada a angústia na sua forma originária. Este afeto irá se repetir nas diversas formas de angústia de separação que nos acompanham do nascimento à morte: Prevalece como eixo organizador de nossa abordagem (Coelho dos Santos, 2001) a dimensão real do desamparo do homem e, consequentemente, a tendência inescapável que o ser humano tem de construir poderosas ficções que o defendam de sua fragilidade incontornável.

A razão científica, se ela é mesmo racional, precisa admitir que os fenômenos inconscientes são a prova de que o homem é habitado pela fantasia, pelo sonho, isto é, pela realidade psíquica. Freud reafirma muitas vezes a tese, de que o "desamparo é a fonte de todos os motivos morais". O nascimento da moralidade é uma consequência do traumatismo do nascimento, momento inaugural em que o real se apresenta sem um grande Outro que Ihe de um sentido. Neste momento, o grito da criança é um significante solitário (S1). Não se articula ainda a ele nenhum Outro significante (S2) que possa interpretar seu significado. (Coelho dos Santos, 2016, p. 8-9)

A constituição do sujeito depende da função do significante no campo da fala e da linguagem e, por essa razão se produz uma duplicação em suas relações com o outro (seu semelhante, sua imagem) e o Outro (lugar onde se constitui o eu que fala com aquele que ouve). De acordo com Lacan (1955-1956/1985, p. 308) há sempre um Outro além de todo diálogo concreto, de todo jogo interpsicológico. Razão pela qual, ele acrescenta: "Não se pode fazer análise de alguém para quem o Outro não existe" (Lacan, 1955-1956/1985, p. 309). Se há sempre um Outro que escuta e interpreta

Revista aSEPHallus de Orientação Lacaniana. Rio de Janeiro, 15(30), 26-40, mai. 2020 a out. 2020.

Help line: relato de experiência sobre um dispositivo de acolhimento aos profissionais de saúde durante 
aquele que fala, é preciso situar o que é esse Outro na fantasia de um sujeito. Porém, é preciso saber levar em conta que para os sujeitos psicóticos, diferentemente, o Outro é absoluto, radical e não apenas um intérprete. A resposta dos sujeitos a um evento traumático como essa pandemia vai evidenciar, necessariamente, a estrutura psíquica prévia de cada um.

Já faz algum tempo (Coelho dos Santos, 2015) que adotamos o ponto de vista de que a saúde física e mental é essencialmente uma questão de responsabilidade subjetiva. É preciso situar essa responsabilidade subjetiva na relação que cada um estabelece com o Outro, circunscrevendo-a no campo da fala e da linguagem. O campo do imaginário e as ficções que um sujeito é levado a inventar são uma bússola imprescindível. Quais as principais ficções que os sujeitos produziram como resposta à situação traumática durante os primeiros meses da pandemia? Desenvolveremos esse trabalho discorrendo sobre a relação entre fiç̧ão e experiência traumática, mas primeiramente vamos justificar a necessidade de invenção de um novo dispositivo de acolhimento que visasse prevenir a eclosão de reações disruptivas no ambiente de trabalho.

\section{Saúde física e mental do colaborador}

Partimos do princípio de que a identificação correta das vulnerabilidades psíquicas no momento em que são desencadeadas e a intervenção terapêutica precoce permitem minimizar problemas de ordem psicológica, conflitos e mesmo erros ${ }^{1}$. Um profissional esgotado não dispõe de energia física e mental para cuidar de outra pessoa. O equilíbrio mental é uma condição indispensável para o enfrentamento de uma situação de crise. Um profissional de saúde psicologicamente abalado pode produzir situações inseguras tanto para si próprio quanto para aqueles que estão sob seu cuidado.

Nos primeiros momentos da pandemia, a coordenadora do serviço que é também uma das autoras deste artigo, produziu um folheto com orientações de autocuidado e recomendações para a manutenção da saúde mental durante a quarentena, o qual foi discutido minuciosamente por todo o grupo. Na versão final, utilizamos uma linguagem simples e direta com sugestões sobre como lidar com o excesso de informações, a fadiga física e emocional, os pensamentos negativos e o desamparo emocional. No final do folheto, indicamos um número de celular para o qual o funcionário deveria ligar se estivesse se sentindo angustiado.

Esta medida foi essencial para um imediato acolhimento e contenção precoce das angústias intensas daqueles colaboradores que mais se sentiram ameaçados. Por meio do número de telefone disponibilizado nos diversos setores do hospital foi possível receber e acolher com agilidade os pedidos de ajuda. Os atendimentos foram realizados por via remota (telefone) e tiveram duração média de 30 minutos. A categoria profissional que mais recorreu aos nossos serviços foi a dos técnicos de enfermagem e dos enfermeiros.

Revista aSEPHallus de Orientação Lacaniana. Rio de Janeiro, 15(30), 26-40, mai. 2020 a out. 2020.

Help line: relato de experiência sobre um dispositivo de acolhimento aos profissionais de saúde durante 
Essa nova forma de trabalho permitiu que atendêssemos uma grande quantidade de pessoas e pudéssemos avaliar a urgência subjetiva de cada um. A escuta da particularidade do caso permitiu identificar as situações de maior risco subjetivo orientando cada um para o melhor cuidado possível. Nos chamados recebidos observamos a recorrência de alguns temas.

Muitos dos funcionários atendidos relataram intensa preocupação em relação a se tornarem veículos da disseminação do vírus para suas respectivas famílias. Temiam ser os responsáveis pelo contágio de familiares e causadores de sua morte. Em outras palavras, receavam "levar o vírus para casa" e fantasiavam angustiados pelo sentimento de virem a ser os "assassinos involuntários" de seus próprios pais, cônjuges e filhos. Por causa desse risco alguns decidiram sair de suas residências, porém, sofriam excessivamente com o afastamento de seus entes queridos num momento de tanta fragilidade. Outra reação psicológica que se repetiu relacionava-se com a certeza fantasmática de contaminação que seria seguida do desencadeamento de sintomas graves. Ameaçados pela constante percepção de ameaça, alguns desses colaboradores interpretavam sintomas inconscientes como se fossem físicos, o que corroborava a crença de que estavam contaminados. Convencidos de que estavam doentes, realizavam o teste para o Covid-19 com frequência desnecessária.

Os efeitos da infecção pelo novo vírus em cada organismo são imprevisíveis. Sabemos que em algumas pessoas os sintomas são imperceptíveis enquanto outras desenvolvem sintomas leves. Há ainda um considerável número de indivíduos que apresentam a forma grave da doença, correm risco de morte e necessitam de internação em terapia intensiva para receber suporte avançado de vida. Cada sujeito precisa lidar com o fato de que está frente a uma situação na qual a tônica é a imprevisibilidade, a contingência, o acaso.

\section{O Outro institucional e o Outro de cada um}

Angustiado frente às incertezas é preciso que o sujeito encontre um Outro que possa the devolver um mínimo de estabilidade emocional. Esta é uma necessidade incontornável, pois a condição originária do desamparo humano, além de insuperável e determinante, instaura a dependência a um Outro que sustenta e estabiliza a consistência subjetiva. Há sempre um Outro em quem o sujeito acredita e é justamente essa relação ao Outro que irá mediar as demais relações a serem estabelecidas na vida social.

A resposta de cada um em uma situação de crise está diretamente relacionada à maneira como se constituiu como sujeito na relação com o Outro. Nos dias de hoje, infelizmente:

O Outro, a lei simbólica, a castração que divide o sujeito, são estruturas permanentemente confrontadas, recusadas e desmentidas. Defendo que se trata de pura radicalização histérica, rebelde a toda forma de autoridade, pronta a revelar que o "rei está nu". Parece que só existe

Revista aSEPHallus de Orientação Lacaniana. Rio de Janeiro, 15(30), 26-40, mai. 2020 a out. 2020.

Help line: relato de experiência sobre um dispositivo de acolhimento aos profissionais de saúde durante

a pandemia covid-19 
satisfação quando transgredimos e ultrapassamos todos os limites. Como se o único desejo fosse o de ser tratado como exceção. (Coelho dos Santos, 2016, p. 7-8)

Nosso trabalho consiste em devolver a cada um a certeza do seu desamparo e a consciência de que ele não pode e não deve prescindir de um Outro que possa ouvir e interpretar seu sofrimento singular. Cada sujeito que escutamos, portanto, nos exige identificar como ele se posiciona frente ao seu desamparo e, a que Outro ele recorre para proteger-se. É preciso localizar os principais referenciais simbólicos que podem auxiliá-lo a se reorganizar psicologicamente. Precisamos estar sensíveis aos efeitos de desencadeamento de uma psicose, até então estabilizada, o que se traduz por meio da emergência inesperada da relação dilacerante a um Outro que pode matá-lo, torturá-lo, debochar dele, humilhá-lo e fazê-lo sofrer apenas porque isso the dá satisfação. Pode-se inferir a repercussão de uma posição como essa, se um sujeito a adota, no relacionamento com os médicos, enfermeiros, técnicos de enfermagem que procuram salvá-lo da doença. $O$ sujeito que desencadeia uma psicose pode interpretar esses cuidados médicos como caprichos torturantes de um Outro que Ihe quer mal.

$\mathrm{Na}$ maioria das ligações telefônicas, as intervenções feitas pelas psicólogas visavam interromper a proliferação de fantasias angustiantes, construções imaginárias - geralmente neuróticas - inspiradas pelo medo excessivo e pelo pânico diante das informações confusas. Tomamos o cuidado de transmitir informações claras e simples acerca da doença contornando a pesada disseminação de ideias precipitadas e confusas. Essa pandemia de desinformação e de politização foi bastante comentada:

Assim, o maior problema que essa doença chamada Covid-19 nos trouxe foi a desorientação no exercício da prática médica tanto na saúde pública quanto na privada. Os efeitos psicopatológicos mais comuns sobre a opinião pública, dessa desorientação, foram a disseminação do pânico. Alguns indivíduos reagiram ao conflito de versões com uma indiferença defensiva aos arautos do perigo. A má qualidade da informação científica veiculada pela imprensa pode explicar-se pelo fato de que entre os colegas cientistas e os médicos assistentes, faltou um mínimo de consenso. Alguns pesquisadores que considero altamente competentes e qualificados foram incapazes de transmitir de forma clara e ordenada seus conhecimentos sobre a doença, auxiliando a população a tomar decisões bem orientadas. Houve muita pressa em convencer a opinião pública das virtudes do isolamento e para isso os formadores de opinião não mediram esforços para pintar um quadro dantesco da infecção. (Coelho dos Santos, 2019, p. 10)

Revista aSEPHallus de Orientação Lacaniana. Rio de Janeiro, 15(30), 26-40, mai. 2020 a out. 2020.

Help line: relato de experiência sobre um dispositivo de acolhimento aos profissionais de saúde durante 
Era preciso auxiliar o sujeito a diferenciar suas fantasias da realidade objetiva de seu adoecer. Essas intervenções, algumas vezes bem simples, permitiram que as pessoas com recursos psíquicos e cognitivos mínimos - tais como: informações precisas e orientações claras e objetivas - tivessem sua angústia apaziguada em um único contato. Para isso, a supervisora do serviço recomendou a todas as psicólogas a estudar o assunto e aprender constantemente mais um pouco sobre a nova doença. Desse modo a equipe preparou-se também para distinguir melhor o que havia de fantasioso no cenário que um determinado sujeito pintava para nós. Ao mesmo tempo, essa estratégia levou a equipe a construir expectativas mais realistas sobre a gravidade de cada caso, diminuindo também a angústia do psicólogo provocada pela margem excessiva de incerteza. A redução da incerteza sobre o grau de gravidade de cada situação conferiu às intervenções dos psicólogos um peso de convicção muito maior, evitando o sentimento desagradável de impostura que a conduta acolhedora e apaziguadora muitas vezes provoca no profissional.

Algumas vezes o sujeito que procurava a help line já estava completamente desestabilizado. Nesses casos pudemos identificar que a urgência subjetiva já estava anunciada. Sabemos que muitos profissionais de saúde trazem uma pesada bagagem de conflitos familiares, tensões conjugais, ressentimentos em relação a pais e irmãos que são, geralmente, a causa do desencadeamento de transtornos psicológicos no ambiente de trabalho. Uma crise na saúde de proporções tão enormes é uma ocasião privilegiada para desestabilizar indivíduos psicologicamente vulneráveis. Foi necessário, então, ampliar nosso escopo de atuação e utilizar outros dispositivos, como avaliação pela medicina do trabalho, encaminhamentos para a psiquiatria e inclusão no programa institucional de atenção à saúde psicológica do trabalhador. Abaixo ilustraremos algumas dessas situações com vinhetas clínicas. $\mathrm{Na}$ avaliação de cada caso observamos algumas reações inconscientes singulares e identificamos quais os recursos psíquicos utilizados por cada um para suportar os momentos de maior angústia. Verificamos a importância da satisfação no trabalho como proteção contra o desamparo generalizado provocado pela pandemia. Quando o sujeito é capaz de efetuar uma articulação sólida entre a posição simbólica que ocupa no mundo e a sua atividade laboral, torna-se mais fácil encontrar uma saída singular frente ao desconhecido. Entretanto, quando um sujeito produzia enredos imaginários (ficções e fantasias catastróficas) que adquiriam maior intensidade que os recursos simbólicos que ele dispunha para interpretá-los e dissolvê-los, suas reações inconscientes eram desproporcionais à gravidade dos eventos e ele terminava colocando em risco sua ligação com o seu trabalho. Alguns chegaram a pedir demissão ou a provocar situações que levassem a instituição a demiti-los.

\section{Observações clínicas de padrões relevantes}

Um padrão típico de fragilidade psíquica generalizada prévia à pandemia foi observado naqueles casos em que o sujeito fazia relatos catastróficos acerca da falta de equipamentos de

Revista aSEPHallus de Orientação Lacaniana. Rio de Janeiro, 15(30), 26-40, mai. 2020 a out. 2020.

Help line: relato de experiência sobre um dispositivo de acolhimento aos profissionais de saúde durante

a pandemia covid-19

Tania Coelho dos Santos, Fernanda Saboya Almendra \& Manuela Itapary Ribeiro 
proteção individual. Convencido do seu abandono pelo Outro institucional, desferia acusações e queixas contra as autoridades que deveriam protegê-lo e se refugiava na posição de vítima. Como a equipe de psicologia estava atuando dentro dos hospitais sabíamos que esse cenário fantasmático de escassez de EPIs não estava de acordo com a realidade. As instituições hospitalares em questão sempre privilegiaram a manutenção dos protocolos de segurança, garantindo o fornecimento de equipamentos de proteção necessários e suficientes, além dos treinamentos de paramentação e desparamentação para sua utilização adequada e eficiente. A principal reflexão que a psicanálise aplicada nos impõe, como antecipamos acima, é a de delimitar de que Outro se trata em cada caso. Tomamos assim o caminho traçado em Os afetos e a dimensão real da relação ao Outro, projeto de investigação em curso, financiado pelo CNPq $(2018-2022)^{2}$ que problematiza essa relação de dependência incontornável de cada um ao Outro de sua pré-história como sujeito. A pergunta essencial é: o que cada um representou para o Outro que o trouxe ao mundo? Como este Outro foi simbolizado, representado inconscientemente pelo sujeito?

Seja na clínica do sujeito, seja na clínica da civilização, são os sintomas, discursos e laços sociais que nos ocupam. Por esta razão fui conduzida a privilegiar nesta nova proposta, os afetos que denunciam a relação dos seres falantes ao Outro. Os afetos são o que existe de mais real. Seja para amá-lo, seja para odiá-lo, seja para ignorá-lo, a existência do Outro simbólico é para cada um, uma dimensão real em jogo no laço social. (Coelho dos Santos, CNPq 2018-2022, s/p)

Somente com essa chave poderemos entender por que alguns indivíduos demandavam garantias inalcançáveis de segurança e, frente à constatação da impossibilidade de garantias absolutas, supunham que se tratava de má vontade do Outro institucional. Esse conceito de Outro institucional inspira-se na análise efetuada por Lebrun (2009) sobre as características do exercício da autoridade nas sociedades pós-modernas. A lógica do não-todo expandiu-se velozmente no tecido social, engendrando novas subjetividades que manifestam uma atitude de desconfiança, temor e rejeição às figuras de autoridade que representam o Outro institucional. Para além dos sentimentos de insegurança e temor, que podem paralisar o sujeito, observamos em alguns casos a emergência de uma atitude de revolta em relação ao Outro institucional (Lebrun, 2009), que provavelmente préexistia. Para alguns sujeitos a instituição ocupa o lugar imaginário daquele Outro mau que oprime, rejeita, dejeta e imobiliza. Essa conviç̧ão transparecia na atividade laboral por meio de uma atitude de desconfiança em relação aos colegas de trabalho e chefias. Os sentimentos de raiva e insegurança, nestes casos, não pareciam emergir da realidade que os cercava mas, pareciam derivar de uma forma pré-existente de relação do sujeito a um Outro supostamente de má vontade.

Revista aSEPHallus de Orientação Lacaniana. Rio de Janeiro, 15(30), 26-40, mai. 2020 a out. 2020.

Help line: relato de experiência sobre um dispositivo de acolhimento aos profissionais de saúde durante 
Retomando a formulação freudiana de que "o desamparo é fonte de todos os motivos morais" em particular, me interessam os fundamentos do "amor ao pai" e do sentimento de reconhecimento da dívida simbólica para com ele. Os indivíduos conservadores tendem a perceber deste modo o fundamento real do laço social. Não estão livres da suspeita, é claro, de um certo pathos conformista. A servidão voluntária, o masoquismo, a sujeição patológica habita aqueles que sacrificam seu desejo para permanecerem fantasmáticamente na posição de objeto amado pelo Outro. No outro polo, encontramos indivíduos marcados pelo "ódio ao pai" e pelo sentimento de rebeldia parricida perante um Outro que é percebido como fundamentalmente mau e injusto. O pathos revolucionário, termo que encontramos em Hanna Arendt (2016), parece cunhado para descrever esta atitude. (Coelho dos Santos, 2018$2022, s / p)$

Através dos contatos telefônicos foi possível identificar casos em que o laço com a instituição e com o próprio trabalho eram demasiado frágeis. A escuta cuidadosa nos permitiu identificar qual era a posição subjetiva em jogo e intervir nesta estrutura considerando a relação de cada um com o trabalho e com a instituição. Auxiliar o sujeito a se responsabilizar por sua escolha profissional sem negligenciar sua autopreservação (autocuidado e cumprimento das medidas de proteção adequadas), foi a orientação que adotamos na tentativa de garantir a melhor atuação possível de cada profissional de saúde frente a uma situação de crise.

Para exemplificar, trazemos uma vinheta clínica. Trata-se de uma jovem enfermeira que se queixava de um sentimento de tristeza, angústia e medo diante do futuro. A enfermeira procurou assistência psicológica esperando preservar seu trabalho e não adoecer psicologicamente. Ela se apresentou dizendo as seguintes frases: _eu não posso sair de licença psiquiátrica" e _ "eu preciso participar desse momento junto com a minha equipe". Em sua narrativa, ela mencionava uma angústia depressiva previamente existente que se intensificou durante a crise desestabilizadora do ambiente de trabalho provocada pela pandemia. Foi possível identificar em sua fala um intenso desejo de "fazer parte", de ajudar os pacientes e de ser mais útil na rotina de trabalho. O conflito entre a vontade de ajudar os outros e as ideias depressivas e autodepreciativas se manifestava nas seguintes expressões: _" eu tenho medo de não dar conta" e _ "eu tenho o desejo de abandonar o barco".

A relação com o Outro institucional revelou ser positiva e expressava-se no laço de confiança estabelecido com as lideranças do setor. Esta funcionária declarou que era muito grata à sua chefia, pois esta sempre a ajudou e a apoiou em seu trabalho. Ela também relatou que se sentia segura para exercer suas tarefas na instituição, uma vez que teve acesso a todos os equipamentos materiais necessários para sua proteção. O laço libidinal com os colegas de trabalho e o sentimento de união

Revista aSEPHallus de Orientação Lacaniana. Rio de Janeiro, 15(30), 26-40, mai. 2020 a out. 2020.

Help line: relato de experiência sobre um dispositivo de acolhimento aos profissionais de saúde durante

a pandemia covid-19

Tania Coelho dos Santos, Fernanda Saboya Almendra \& Manuela Itapary Ribeiro 
frente a um inimigo comum a fortaleceu e permitiu que ela continuasse o seu trabalho dentro da UTI de isolamento do Covid-19. Visto que foi identificada a existência um transtorno psicológico prévio, a psicóloga que a acolheu por meio da ligação telefônica recomendou que ela procurasse o programa institucional de atenção à saúde do trabalhador. Conforme explicitado no início deste texto, este programa é uma atividade regular do serviço de psicologia da instituição e visa a prevenção, diagnóstico e tratamento de transtornos psicológicos que interferem na capacidade laboral e qualidade de vida dos funcionários do hospital.

Para contrapor a vinheta apresentada, desejamos destacar que também foi possível identificarmos atitudes reivindicativas e acusatórias em relação ao ambiente de trabalho. Nesses casos, a razão da revolta dirigida à instituição não parecia corresponder à realidade dos fatos. Por algum motivo, esses sujeitos interpretavam a autoridade e hierarquia institucional como um Outro opressor. A questão nos interessa, pois aponta para a radicalidade de duas atitudes distintas. De um lado, uma posição subjetiva que enseja um laço com o Outro institucional não conflituoso e facilita a adaptação à situação imprevista e adversa. De outro, uma posição subjetiva que rejeita a legitimidade da autoridade institucional pois desconfia que ela tem má-intenção. Essa posição vai levá-la a desqualificar, desmoralizar esse Outro institucional e exigir reparação por supostos danos fantasiosos e imaginários.

Exemplificamos com mais uma vinheta clínica. Trata-se de um técnico de enfermagem solteiro que relatou sentir-se "constantemente ameaçado, muito ansioso e inseguro para exercer o seu trabalho". Por esse motivo a chefia do rapaz antecipou o dia de folga de forma que ele pudesse procurar assistência médica. O técnico não atuava na UTI de isolamento, portanto não estava atendendo diretamente pacientes de Covid-19. Como os demais funcionários, ele havia recebido todos os treinamentos indicados e tinha acesso aos equipamentos de autoproteção necessários à sua atividade laboral.

O médico psiquiatra que o rapaz consultou (que não fazia parte do corpo clínico da instituição) considerou depois de uma cuidadosa avaliação, que ele estava em condições de trabalhar. Por essa razão, não the concedeu um atestado médico que justificasse o afastamento da atividade laboral. O colaborador se ressentia por não ter sido tratado com "empatia", uma vez que considerava estar "doente". Este técnico de enfermagem não pretendia deixar de trabalhar, mas esperava que a chefia e os colegas entendessem sua fragilidade e o preservassem quando estivesse "nervoso". Este sintoma psicológico era acompanhado da expectativa de ser tratado como exceção. Este rapaz não compreendia que também os demais colegas estavam igualmente submetidos à mesma situação de estresse que ele. Foi preciso levá-lo a ultrapassar o sentimento de que estava sozinho nessa situação e responsabilizar-se em compartilhar essa experiência de forte estresse psicológico, coletivamente.

Revista aSEPHallus de Orientação Lacaniana. Rio de Janeiro, 15(30), 26-40, mai. 2020 a out. 2020.

Help line: relato de experiência sobre um dispositivo de acolhimento aos profissionais de saúde durante 


\section{Conclusões}

Concluímos que a experiência de uma crise na saúde coletiva como esta que foi causada pela pandemia de Covid19, traz à tona a posição de cada um diante da ameaça do desamparo. Nesse momento, evidenciam-se os recursos internos disponíveis para cada um enfrentar o imprevisível. 0 trabalho de atenção à saúde do trabalhador vem nos ensinando a relevância do laço que cada sujeito estabelece com sua escolha profissional. Esta é uma dimensão do Outro. Amar e trabalhar, como Freud nos ensinou são os nossos maiores desafios como adultos. O lugar simbólico que a atividade laboral ocupa para cada um é reveladora da qualidade da relação com o Outro que um sujeito adulto pode desenvolver.

A help line serviu como dispositivo de acolhimento e intervenção em situações de urgência subjetiva deflagrada pela situação de doença e ameaça de perda. Ainda que este dispositivo possua limitações óbvias, se mostrou eficaz para o acolhimento e contenção de angústias. Além disso, nos mostrou que a forma como cada sujeito estruturou os laços sociais influencia diretamente a resposta que produz frente a uma situação de crise. Ou seja, a relação particular que cada sujeito estabelece com o Outro estrutura o laço institucional e manifesta-se na rotina de trabalho, facilitando ou dificultando a adaptação e a construção de soluções saudáveis em momentos de crise.

\section{Notas}

1. A literatura sobre qualidade em serviços de saúde aponta para a estreita relação entre o nível de estresse do profissional de saúde e a ocorrência de eventos adversos e erros que podem resultar em danos ao paciente. (Departamento de Psicologia da Associação de Medicina Intensiva Brasileira, 2020).

2. Coelho dos Santos, T. Projeto de Pesquisa 2018-2022: Os afetos e a dimensão real da relação ao Outro, financiado com recursos do programa de bolsas de produtividade científica.

\section{Referências Bibliográficas}

Coelho dos Santos, T. (2001). Quem Precisa de Análise Hoje? O discurso analítico: novos sintomas e novos laços sociais. São Paulo: Bertrand Brasil.

Coelho dos Santos, T. (Org.). (2005). Efeitos terapêuticos na psicanálise aplicada. Rio de Janeiro: Contra Capa.

Coelho dos Santos, T. (2015). Responsabilidade coletiva e responsabilidade subjetiva: saúde é um direito ou um dever? In R. M. Barros \& V. Darriba (Orgs.), Psicanálise e saúde: entre o estado e o sujeito. Rio de Janeiro: Companhia das Letras.

Revista aSEPHallus de Orientação Lacaniana. Rio de Janeiro, 15(30), 26-40, mai. 2020 a out. 2020.

Help line: relato de experiência sobre um dispositivo de acolhimento aos profissionais de saúde durante a pandemia covid-19

Tania Coelho dos Santos, Fernanda Saboya Almendra \& Manuela Itapary Ribeiro 
Coelho dos Santos, T. (2016). Desmentido ou inexistência do Outro: a era da pós-verdade. Revista aSEPHallus de Orientação Lacaniana, 11(22), 4-19. Recuperado de http://www.isepol.com/asephallus/numero 22/pdf/2-

Desmentido ou inexistencia do Outro.pdf. doi: 10.17852/1809-709x.2019v11n22p04-19

Coelho dos Santos, T. (2018-2022). Os afetos e a dimensão real da relação ao Outro. Rio de Janeiro: Projeto de pesquisa para o CNPq relativo ao período 2018/2022.

Coelho dos Santos, T. (2019). Versões contraditórias no campo da ciência: politização e desinformação na prevenção à Covid-19. Revista aSEPHallus de Orientação Lacaniana, 15(29), 6-22. Recuperado de http://www.isepol.com/asephallus/pdf/02\%20\%20TANIA\%20COELHO\%20DOS\%20SANTOS.pdf. $\quad$ doi: 10.17852/1809709x.2020v15n29p06-22

Coelho dos Santos, T. (2020a). A irrupção do privado no espaço público. In: F. P. Ferreira \& J. Verztman (Orgs.). O público na psicanálise. (pp. 147-158). Rio de Janeiro: Appris.

Coelho dos Santos, T. (2020b). Transtornos psicológicos no trabalho. Projeto de pesquisa em psicanálise aplicada do Edital do CNPq MAI/DAÍ.

Departamento de Psicologia da Associação de Medicina Intensiva Brasileira. (2020). Recomendações para o bem-estar emocional da equipe multidisciplinar durante a pandemia pelo Sars-Cov-2. Recuperado de https://www.amib.org.br/fileadmin/user_upload/amib/2020/marco/18/corona_psico_amib_15 h56 18032020.pdf

Dias, M. de S. F. M.; Coelho dos Santos, T.; Pereira, F. R. C.; Rodrigues, D. R. dos S., \& Costa, E. da S. da G. (2019). Quando o "fique em casa" não era uma opção: os bastidores e os relatos das experiências dos profissionais de saúde no front de combate à pandemia da Covid-19. Revista aSEPHallus de Orientação Lacaniana, 15(29), 118-128. Recuperado de http://www.isepol.com/asephallus/pdf/08\%20-\%20MARIANA\%20MEDRADO.pdf. doi: 10.17852/1809-709x.2020v15n29p118-128

Freud, S. (1996). Projeto para uma psicologia cientifica. In J. Salomão (Trad.). Edição Standard Brasileira das Obras Completas de Sigmund Freud (Vol. 1, pp. 355-466). Rio de Janeiro: Imago. (Trabalho original publicado em 1950[1895]).

Lacan, J. (1985). O Seminário Livro 3: As psicoses. Rio de Janeiro: Jorge Zahar Editor. (Trabalho original publicado em 1955-1956).

Lebrun, J-P. (2009). Clínica da instituição: o que a psicanálise contribuiu para a vida coletiva. Porto Alegre: CMC Editora.

Moreira, M. I. R., \& Coelho dos Santos, T. (2019). Psicanálise aplicada à instituição: a prática clínica no hospital geral. Revista aSEPHallus de Orientação Lacaniana, 14(28), 125-140. Recuperado

Revista aSEPHallus de Orientação Lacaniana. Rio de Janeiro, 15(30), 26-40, mai. 2020 a out. 2020.

Help line: relato de experiência sobre um dispositivo de acolhimento aos profissionais de saúde durante

a pandemia covid-19

Tania Coelho dos Santos, Fernanda Saboya Almendra \& Manuela Itapary Ribeiro 
Oliveira, F. L. G. de; Coelho dos Santos, T.; Dias, M. de S. F. M., \& Carvalho, P. B. de. (2019). Psicanálise aplicada com profissionais em uma instituição hospitalar: os afetos e a dimensão real do Outro. Revista da SBPH, 22(spe), 157-173. Recuperado de http://pepsic.bvsalud.org/scielo.php?script=sci arttext\&pid=S1516-08582019000200012

Organização Mundial da Saúde. (2020). Guia com cuidados para saúde mental durante a pandemia. Recuperado de https://news.un.org/pt/story/2020/03/1707792

Saboya, F.; Coelho dos Santos, T.; Moreira, M. I. R., \& Castro, M. G. S. R. de. (2019). Psicanálise aplicada ao contexto hospitalar: intervenções em tempo de pandemia Covid-19. Revista aSEPHallus de Orientação Lacaniana, 15(29), 92-102. Recuperado de http://www.isepol.com/asephallus/pdf/06\%20-\%20FERNANDA\%20SABOYA.pdf. doi: 10.17852/1809-709x.2020v15n29p92-102

Citação/Citation: Coelho dos Santos, T., Saboya Almendra, F., Itapary Ribeiro Moreira, M. (mai. 2020 a out. 2020). Help line: relato de experiência sobre um dispositivo de acolhimento aos profissionais de saúde durante a pandemia covid-19. Revista aSEPHallus de Orientação Lacaniana, 15(30), 26-40. Disponível em www.isepol.com/asephallus. Doi: 10.17852/1809-709x.2020v15n30p26-40

Editor do artigo: Tania Coelho dos Santos.

Recebido/Received: 04/03/2020 / 03/04/2020.

Aceito/Accepted: 04/20/2020 / 20/04/2020.

Copyright: (c) 2019 Associação Núcleo Sephora de Pesquisa sobre o moderno e o contemporâneo. Este é um artigo de livre acesso, que permite uso irrestrito, distribuição e reprodução em qualquer meio, desde que o autor e a fonte sejam citados/This is an open-access article, which permites unrestricted use, distribution, and reproduction in any medium, provided the author and source are credited.

Revista aSEPHallus de Orientação Lacaniana. Rio de Janeiro, 15(30), 26-40, mai. 2020 a out. 2020.

Help line: relato de experiência sobre um dispositivo de acolhimento aos profissionais de saúde durante a pandemia covid-19 